\title{
REFORMA DO ENSINO MÉDIO E EDUCAÇÃO REMOTA: O QUE PENSAM OS(AS) ESTUDANTES DO DISTRITO FEDERAL?'
}

\author{
High School Reform and Remote Education: what do students from Distrito \\ Federal think?
}

Marcelo Pinheiro Cigales ${ }^{2}$

Doralice Pereira de Assis ${ }^{3}$

Lucas Sales de Figueredo ${ }^{4}$

Guilherme Henrique Cruz Quevedo ${ }^{5}$

\begin{abstract}
Resumo
0 artigo apresenta resultados parciais de uma pesquisa realizada junto ao projeto de extensão "Acompanhamento e análise do Novo Ensino Médio na área de Ciências Humanas e Sociais Aplicadas", vinculada ao Departamento de Sociologia da Universidade de Brasília, em 2020. 0 objetivo do artigo é compreender a percepção dos estudantes do ensino médio da rede pública do Distrito Federal (DF) sobre a Reforma do Ensino Médio e o ensino remoto implementado a partir do distanciamento social imposto pela pandemia da Covid-19. A metodologia está embasada na aplicação de questionários via Google Forms ${ }^{\circledR}$ com 79 estudantes do primeiro ano do ensino médio de uma escola pública do DF. Entre os resultados da pesquisa, destacam-se: a) a percepção dos respondentes de que o novo currículo é mais atrativo ao diversificar a oferta de ensino; b) a dificuldade de aprendizagem dos(as) estudantes no que se refere ao ensino remoto; e c) a indefinição pela escolha do Itinerário Formativo na parte diversificada do novo currículo.
\end{abstract}

Palavras-chave: Reforma do Ensino Médio; Ensino Remoto; Currículo

\begin{abstract}
The article presents partial results of a research carried out with the extension project Monitoring and analysis of the New High School in the area of Applied Human and Social Sciences, linked to the Department of Sociology of the University of Brasilia (UnB) in 2020. The purpose of the article is to

\footnotetext{
${ }^{1}$ Esta pesquisa foi contemplada com recursos do Edital n ${ }^{\circ}$ 03/2020 de Chamada para Auxílio Financeiro de Atividades de Pesquisa do Departamento de Sociologia da Universidade de Brasília (UnB), e do Edital $\mathrm{n}^{\circ}$ 01/2020 do Decanato de Extensão da UnB, para atividades de Extensão no polo do Recanto das Emas.

2 Professor adjunto do Departamento de Sociologia da Universidade de Brasília (UnB). Coordenador do Laboratório de Ensino de Sociologia Lélia Gonzalez (SOL/UnB). Doutor em Sociologia Política pela Universidade Federal de Santa Catarina (UFSC). marcelo.cigales@unb.br

3 Graduanda em Ciências Sociais pela Universidade de Brasília. Integra o Laboratório de Ensino de Sociologia Lélia Gonzalez. doralice.assis@hotmail.com

4 Graduando em Ciências Sociais pela Universidade de Brasília. Integra o Laboratório de Ensino de Sociologia Lélia Gonzalez. 1sales490@gmail.com

5 Graduando em Ciências Sociais pela Universidade de Brasília. Integra o Laboratório de Ensino de Sociologia Lélia Gonzalez. guilhermequevedo@hotmail.com (bolsista CAPES, PIBID).
} 
Reforma do ensino médio e educação remota: o que pensam os(as) estudantes do distrito federal?| Marcelo Pinheiro Cigales | Doralice Pereira de Assis | Lucas Sales de Figueredo \& Guilherme Henrique Cruz Quevedo

understand the perception of public high school students in the Federal District about the Reform of High School and Remote Education implemented from the social distance imposed by the health crisis of COVID19. The methodology is based on the application of forms via Google Forms with 79 students from the first year of high school at a public school in DF. Among the survey results, the following stand out: a) the respondents' perception that the new curriculum is more attractive when it diversifies the teaching offer; b) the students' learning difficulties regarding Remote Teaching; and c) uncertainty regarding the choice of the Formative Itinerary in the diversified part of the new curriculum.

Keywords: High School Reform; Remote Education; Curriculum.

\section{Introdução}

Desde a criação do Ministério da Educação e Saúde Pública em 1930, houve diversos momentos em que grupos com interesses divergentes, no âmbito do campo religioso, político ou econômico, protagonizaram disputas acirradas para a implementação de suas ideias e projetos no campo educacional brasileiro. O Manifesto dos Pioneiros da Educação Nova (1932), que resultou do embate entre católicos e liberais ao redor de uma educação pública, gratuita e laica, representa uma dessas disputas. Com efeito, as ideias do Manifesto também reverberaram nas décadas seguintes que antecederam a aprovação da primeira Lei de Diretrizes e Bases (1961), onde intelectuais como Florestan Fernandes levantaram novamente a bandeira da escola pública e gratuita, em oposição aos interesses de grupos advindos de uma elite econômica com interesses privatistas no campo educacional (FERNANDES, 1966).

Parece que o atual cenário não se distancia daquele da década de 1930 e 1960, afinal o que está em disputa no sistema educacional capitalista ocidental é o monopólio da violência simbólica (BOURDIEU; PASSERON, 1992), voltada para a perpetuação dos privilégios das classes dominantes que, no caso brasileiro, não parecem ocupar a escola pública, mas ainda assim procuram ditar as regras políticas, econômicas e curriculares. Política porque impedem, por meio de estratégias de consensualização e concertação discursiva (MICHETTI, 2020), a construção de uma educação emancipadora, na qual a crítica e a pluralidade de ideias, pessoas e instituições estejam presentes em sua constituição. Econômica porque na base do capitalismo 
Reforma do ensino médio e educação remota: o que pensam os(as) estudantes do distrito federal?| Marcelo Pinheiro Cigales | Doralice Pereira de Assis | Lucas Sales de Figueredo \& Guilherme Henrique Cruz Quevedo

ocidental a educação ou os sistemas de ensino devem servir sobretudo ao capital refletido no lucro de corporações e grupos financeiros internacionais. E curricular, uma vez que o novo capital, o capital cultural (BOURDIEU, 1996), uma vez democratizado, pode abalar as desigualdades em que se assenta nossa sociedade, que até permite a ascensão de determinados indivíduos, mas dificilmente de grupos ou coletivos, sob o risco de dar voz à "maioria silenciada", nos termos de Lélia Gonzalez (RATTS; RIOS, 2010).

Partimos de uma literatura crítica para analisarmos esse processo, bem como buscamos considerar elementos da conjuntura empírica para ampliarmos e flexionarmos críticas estruturalistas e funcionalistas sobre o currículo escolar, pois consideramos tanto as "consequências impremeditadas da ação" (GIDDENS, 2009) quanto a concepção de que o currículo é um campo social de disputas, onde o que é prescrito nem sempre corresponde ao que é vivido. Nesse sentido, podemos considerar a "recontextualização pedagógica" (BERNSTEIN, 1996) e política do currículo a partir da visão de quem faz e refaz o currículo na escola.

Este artigo compõe um projeto de pesquisa e extensão intitulado "Acompanhamento e análise do Novo Ensino Médio na área de Ciências Humanas e Sociais Aplicadas no Distrito Federal", vinculado ao Observatório da Educação e do Novo Ensino Médio (registrado no Conselho Nacional de Desenvolvimento Científico e Tecnológico) da Coordenadoria de Integração das Licenciaturas (CIL/UnB) e que abrange outras áreas, como: Ciências da Natureza e suas Tecnologias, Linguagens e suas Tecnologias e Matemática e suas Tecnologias. Esse projeto visa acompanhar a implementação da Reforma do Ensino Médio, por meio de questionários e entrevistas com professores, estudantes e gestores das escolas-piloto do Distrito Federal (DF). No artigo, apresentamos dados de um questionário respondido por 79 estudantes do primeiro ano do ensino médio de uma escola-piloto do DF. Destacamos que o questionário foi construído coletivamente entre professores, estudantes bolsistas e voluntários que integram o Observatório da Educação e do Novo Ensino Médio (CIL/ Universidade de Brasília). Optamos, neste trabalho, por evidenciar os dados de apenas uma instituição de ensino, tendo em vista dois 
Reforma do ensino médio e educação remota: o que pensam os(as) estudantes do distrito federal?| Marcelo Pinheiro Cigales | Doralice Pereira de Assis | Lucas Sales de Figueredo \& Guilherme Henrique Cruz Quevedo

fatores: a) o apoio financeiro por meio de uma bolsa de extensão para estudante de graduação, visto que o projeto foi contemplado por edital público que direcionava as ações para a região em que a escola está localizada (Recanto das Emas); b) o esforço por compreender as características da instituição escolar e da cidade administrativa em questão, de forma a criar hipóteses ou conceitos que possam ser discutidos em futuras pesquisas, quando da comparação com as outras escolas-piloto do DF.

A seguir, abordamos a atual configuração curricular das Ciências Humanas no DF, apontando alguns caminhos que se desenham a partir da implementação da Reforma do Ensino Médio. Na sequência, apresentamos os dados empíricos, coletados por meio de questionário online, respondido por estudantes do primeiro ano do ensino médio que vivenciam as transformações curriculares em curso, assim como da implementação do ensino remoto devido à Covid-19.

\section{As Ciências Humanas no Currículo em Movimento do Distrito Federal}

A pesquisa foi planejada no contexto pré-pandêmico, o que exigiu, a partir de março de 2020, uma série de ações voltadas para a superação da ausência física nas escolas pesquisadas. Segundo Ferreira, Abreu e LouzadaFilho (2020), o DF havia planejado, em 2020, a implementação da Reforma do Ensino Médio em cinco escolas da rede pública, denominadas de "escolaspiloto" e que, posteriormente, serviriam de base para a aplicação do novo modelo curricular nas demais instituições de ensino. No entanto, o contexto pandêmico fez com que a implementação do novo currículo esteja sendo realizada no contexto do ensino remoto.

O governador do Distrito Federal, Ibaneis Rocha, em 11 de março de 2020, com o Decreto $n^{\circ} 40.509$, Artigo 2 do parágrafo II, suspendeu pelo prazo de cinco dias "[...] as atividades educacionais em todas as escolas, universidades e faculdades, das redes de ensino pública e privadas" (DISTRITO FEDERAL, 2020a). A suspensão das atividades foram renovadas por outros Decretos, tais como: $\mathrm{n}^{\circ} 40.520$, de 14 de março (DISTRITO 
Reforma do ensino médio e educação remota: o que pensam os(as) estudantes do distrito federal?| Marcelo Pinheiro Cigales | Doralice Pereira de Assis | Lucas Sales de Figueredo \& Guilherme Henrique Cruz Quevedo

FEDERAL, 2020b), $\mathrm{n}^{\circ}$ 40.539, de 19 de março (DISTRITO FEDERAL, 2020c), $\mathrm{n}^{\circ}$ 40.550, de 23 de março (DISTRITO FEDERAL, 2020d), $\mathrm{n}^{\circ} 40.583$, de 1 de abril (DISTRITO FEDERAL, 2020e), $\mathrm{n}^{\circ}$ 40.817, de 22 de maio (DISTRITO FEDERAL, 2020f), e no 40.939, de 2 de julho (DISTRITO FEDERAL, 2020g), uma vez que, seguindo as orientações dos agentes de saúde e órgãos internacionais como a Organização Mundial da Saúde (OMS), havia a recomendação do distanciamento social, tendo em vista que o vírus SARSCoV-2, que causa a doença Covid-19, é altamente contagioso e, na maioria das vezes, circula entre pessoas assintomáticas (GARCIA, 2020).

Tendo esse cenário em questão, o DF optou pelo retorno das aulas de forma remota no dia 13 de julho de 2020, sendo posteriormente adiado para o dia 31 de agosto (ANTUNES, 2020), mobilizando uma série de agentes contrários a essas medidas, uma vez que uma parcela significativa dos estudantes não teria condições adequadas de infraestrutura, como internet ou computadores, para acessar o conteúdo a partir de suas casas (CARLA, 2020). Até o fechamento deste artigo, em novembro de 2020, o cenário educacional no DF continua com a orientação para o ensino remoto.

Em meio a essas circunstâncias, o Observatório da Educação e do Novo Ensino Médio e os projetos que o integram, planejaram um roteiro de questionário para ser respondido pelos estudantes das escolas-piloto que participam da pesquisa. O questionário foi organizado na plataforma do Google Forms ${ }^{\circledR}$, contou com 22 questões fechadas e cinco abertas, e foi respondido por 257 estudantes entre os meses de julho e agosto de 2020. O questionário foi dividido em três blocos: a) informações pessoais e domiciliares; b) conhecimento sobre a nova estrutura curricular do ensino médio; c) vivências e perspectivas sobre o ensino remoto.

Dada a impossibilidade de estarmos fisicamente na escola para o levantamento dos dados da pesquisa, e tendo em vista que a situação do Ensino Remoto Emergencial (ERE)(ARRUDA, 2020) possui uma dinâmica ainda pouco conhecida, optamos por centrar nossa análise em apenas uma escola que participa da implementação da Reforma do Ensino Médio no DF. Assim, para complementar os dados da pesquisa, evidenciamos o Projeto 
Reforma do ensino médio e educação remota: o que pensam os(as) estudantes do distrito federal?| Marcelo Pinheiro Cigales | Doralice Pereira de Assis | Lucas Sales de Figueredo \& Guilherme Henrique Cruz Quevedo

Político Pedagógico (PPP) da instituição, assim como fizemos o acompanhamento de algumas salas de aula virtuais da área de Ciências Humanas e Sociais Aplicadas (CHSA) entre os meses de agosto e novembro de 2020.

Com o advento da pandemia, as observações em sala de aula estão ocorrendo de modo virtual. Até o momento pudemos observar como a escola, professores, administração e equipe pedagógica se articularam para dar continuidade ao plano de implementação do novo modelo curricular no formato virtual. O que constatamos é que houve uma implementação parcial, onde são inseridas as matérias eletivas e o projeto de vida, mas a Formação Geral Básica (FGB) ainda é apresentada por disciplina e não por área de conhecimento, como previsto na reforma. Além disso, a interdisciplinaridade, os objetivos de aprendizagem e a avaliação não estão nítidos nesse formato.

É preciso destacar que a Reforma do Ensino Médio (BRASIL, 2017) e a Base Nacional Comum Curricular (BNCC) (BRASIL, 2018) dividem o ensino médio em duas etapas consideradas indissociáveis: a Formação Geral Básica (FGB) e os Itinerários Formativos (IF). A primeira, com até 1800 horas, tendo explicitamente obrigatórias as disciplinas de Matemática, Língua Portuguesa e Inglês. Na segunda parte, os IF podem ocorrer, de acordo com as condições objetivas das instituições de ensino, a partir de cinco áreas: Matemática e suas Tecnologias, Linguagens e suas Tecnologias, Ciências da Natureza e suas Tecnologias, Ciências Humanas e Sociais Aplicadas e Educação Técnica e Profissional, com carga horária mínima de 1200 horas. Conforme a Portaria MEC $n^{\circ} 1.432 / 2018$, o IF tem quatro eixos estruturantes: a) investigação científica; b) processos criativos; c) mediação e intervenção sociocultural; e d) empreendedorismo. O ensino médio no DF também passa a ser regido pelo sistema de créditos (1 crédito corresponde a 16 horas) e pela semestralidade.

A Secretaria de Estado de Educação do Distrito Federal (SEEDF), desde 2019, tem atuado na reformulação do Currículo em Movimento (2014), apresentando ao Conselho de Educação uma nova versão que passou por 
Reforma do ensino médio e educação remota: o que pensam os(as) estudantes do distrito federal?| Marcelo Pinheiro Cigales | Doralice Pereira de Assis | Lucas Sales de Figueredo \& Guilherme Henrique Cruz Quevedo

duas consultas públicas durante os anos de 2019 e 2020. Na atual versão, a área de CHSA compõe as disciplinas de História, Geografia, Filosofia e Sociologia, tanto na FGB quanto no IF, contendo referências a autores(as) conhecidos na área da Sociologia, tais como: Habermas, Zygmunt Bauman, Stuart Hall, István Mészáros, Charles W. Mills e Boaventura de Sousa Santos (DISTRITO FEDERAL, 2020h).

No contexto da rede de ensino público do DF, são cinco IF (IF de Ciências Humanas e Sociais Aplicadas, IF de Matemática e suas Tecnologias, IF de Linguagens e suas Tecnologias, IF de Ciências da Natureza e suas Tecnologias e IF de Educação Profissional Técnica). O DF está organizando os IF em três unidades curriculares: as eletivas orientadas, as trilhas de aprendizagem e o projeto de vida. Na prática, essas formas de oferta ainda estão sendo experimentadas nas escolas-piloto e, ao final, serão normatizadas em um documento orientador para toda a rede pública. As eletivas orientadas, assim como as trilhas de aprendizagem, poderão ocorrer de forma a contemplar projetos pedagógicos, de extensão e pesquisa, clubes, monitorias, incubadoras, estágios, oficinas, laboratórios, desde que percorram os quatro eixos estruturantes. As eletivas orientadas serão organizadas em um semestre, enquanto as trilhas de aprendizagem em quatro. É preciso destacar que para o projeto de vida, a SEEDF oferta formação para professores (sem requisito de área) para trabalhar com essa forma de ensino, que é prevista para ocorrer nos seis semestres do ensino médio e tem, entre outras orientações, o objetivo de auxiliar os estudantes na escolha das trilhas de aprendizagem e das eletivas orientadas no interior dos IF (DISTRITO FEDERAL, 2020h).

Um dos pontos que questionamos nesta pesquisa é sobre o interesse dos estudantes em optar pelo IF da área de CHSA, uma vez que se houver, ainda temos que considerar as condições objetivas de implementação, em cada escola, de projetos, laboratórios, oficinas, grupos de estudos etc., que poderão ser ofertados para atender essa demanda. Nesse sentido, questionamos: qual a percepção dos estudantes do DF sobre a Reforma do 
Reforma do ensino médio e educação remota: o que pensam os(as) estudantes do distrito federal?| Marcelo Pinheiro Cigales | Doralice Pereira de Assis | Lucas Sales de Figueredo \& Guilherme Henrique Cruz Quevedo

Ensino Médio? Como eles vêm percebendo essas transformações curriculares? Há o interesse pelo IF da área de CHSA?

\section{O que pensam os alunos sobre a Reforma do Ensino Médio?}

Os estudos no subcampo do ensino de Sociologia (FERREIRA; OLIVEIRA, 2015; BRUNETTA; CIGALES, 2019), que dão visibilidade aos estudantes do ensino médio, ainda são raros e esparsos, ainda que a criação do Mestrado Profissional de Sociologia em Rede Nacional (PROFSOCIO) nos últimos anos insira de forma direta os processos educacionais e os agentes escolares nessa seara de pesquisa, pois são pesquisas produzidas por professores(as) de Sociologia que, em muitas vezes, envolvem seu próprio cotidiano pedagógico como objetivo de investigação.

Uma das pesquisas com maior visibilidade na área é a de Rêses (2004), que aborda as representações sociais dos alunos da rede pública do DF sobre a Sociologia no ensino médio. Percebemos que investigar o público escolar neste momento de reforma curricular (estudantes, professores e gestores) é essencial tanto para compreendermos os efeitos positivos e negativos dessa reforma no chão da escola quanto para pensarmos estratégias politicas e acadêmicas que buscam uma educação pública de qualidade, respeitando a pluralidade de vozes e agentes nessa "recontextualização pedagógica" e política (BERNSTEIN, 1996) do currículo escolar.

A seguir, apresentamos os dados do questionário respondido por 79 estudantes do primeiro ano do ensino médio de uma escola pública do DF. No que se refere as informaçoes pessoais, constatamos que a grande parcela dos estudantes (86,6\%) estao na faixa etaria dos 15 e 16 anos. Nesse mesmo sentido, também observamos que as pessoas que se identificam como pardas são a maioria $(59,9 \%)$, seguidas dos brancos $(24 \%)$ e pretos $(15,2 \%)$. Além disso, também corresponde à maioria as estudantes que se identificam com o genero feminino, compondo cerca de $72,1 \%$ da amostra.

Quanto às informações domiciliares, verificamos que $86 \%$ dos respondentes residem na Região Administrativa do Recanto das Emas/DF, 
Reforma do ensino médio e educação remota: o que pensam os(as) estudantes do distrito federal?| Marcelo Pinheiro Cigales | Doralice Pereira de Assis | Lucas Sales de Figueredo \& Guilherme Henrique Cruz Quevedo

sendo que $76 \%$ indicaram que, contando com eles, moram com quatro ou mais pessoas. A Região Administrativa do Recanto das Emas foi criada em 1993, por meio da Lei $n^{\circ}$ 510/93 (DISTRITO FEDERAL, 1993), com o objetivo de atender ao Programa de Assentamento do Governo do Distrito Federal. O nome da região pode ter surgido devido à espécie de arbusto chamado "canelade-ema" ou por conta da predominância da espécie de ave denominada Rhea Americana, também conhecida como ema, que habita o cerrado. Inicialmente, a área prevista para a construção da nova cidade era composta por um núcleo rural chamado Vargem da Benção, constituído por chácaras que foram desapropriadas para a distribuição dos primeiros lotes.

A Pesquisa Distrital por Amostra de Domicílios (PDAD), publicada em 2019, mostra que o Recanto das Emas possui população estimada de 130.043 habitantes, com média de idade de 30,4 anos havendo uma concentração maior entre 20 e 34 anos. Quanto ao nível de escolaridade, dentre a população com 25 anos ou mais, 31,1\% possui ensino médio completo, seguido de $28,8 \%$ com ensino fundamental incompleto, $11,6 \%$ com o ensino superior completo e 3,3\% que não possui escolaridade. Sobre a divisão por sexo, 51,7\% são do sexo feminino e $48,3 \%$ do sexo masculino. No que diz respeito à raça/cor, $52,2 \%$ se identificam como pardo, 32,2\% como branco e 13,6\% como preto.

Considerando a população entre 4 e 24 anos, 58,3\% frequentam instituições de ensino público e 11,5\% instituições de ensino particular. Do total dos alunos do Recanto das Emas, 78,2\% estudam na própria Região Administrativa, 9,4\% em Taguatinga e 5,72\% no Plano Piloto. O principal meio de transporte desses estudantes de casa para a escola é a pé $(50,8 \%)$ e de ônibus $(28,2 \%)$, e o tempo médio de deslocamento é de até 15 minutos (62,2\%). Entre os alunos de 15 a 17 anos, 91\% frequentam a escola e 8,9\% não frequentam (PDAD, 2019).

A Pesquisa Distrital também mostra que, no Recanto das Emas, dentre as pessoas que possuem emprego, 67,3\% desempenham atividades no setor de serviços, 19,5\% no setor de comércio e $9 \%$ no setor de indústria. Quanto à posição ocupada no trabalho principal, 66,8\% é empregado (exceto doméstico) e $20,7 \%$ trabalha por conta própria. Entre os trabalhadores residentes na 
Reforma do ensino médio e educação remota: o que pensam os(as) estudantes do distrito federal?| Marcelo Pinheiro Cigales | Doralice Pereira de Assis | Lucas Sales de Figueredo \& Guilherme Henrique Cruz Quevedo

Região Administrativa Recanto das Emas, 29,4\% trabalham na Região Administrativa I Plano Piloto, 24,6\% na própria RA e 9,5\% em Taguatinga (PDAD, 2019).

Para as questões sobre o conhecimento da nova estrutura do ensino médio foi utilizada uma Escala Likert de 5 pontos, onde 1 demonstra pouca intensidade ou discordância total e 5 muita intensidade ou concordância total. Nessa seção, perguntamos o quanto os estudantes se sentiam bem informados sobre o novo ensino médio. Assim, 24 estudantes responderam a opção 5 (30,38\%), seguidos por 23 estudantes que marcaram a opção 4 (29,11\%), 20 a opção 3 (25,32\%), cinco estudantes a opção 2 e sete estudantes opção 1 , como pode ser visto no Gráfico 1. Sobre o que é a FGB e o que muda com relação ao currículo tradicional, houve uma concentração maior na opção 3 $(29,11 \%)$, seguida pela opção $5(27,85)$ e opção $4(26,58 \%)$. Acerca do projeto de vida, 60,76\% dos alunos marcaram a opção 5, mostrando que, em sua maioria, sentem-se bem informados sobre o tema.

GRÁFICO 1 - PERCEPÇÃO DOS(AS) ESTUDANTES SOBRE O GRAU DE INFORMAÇÃO DO NOVO CURRÍCULO

\section{Sinto-me bem informado(a) sobre o novo Ensino Médio?}

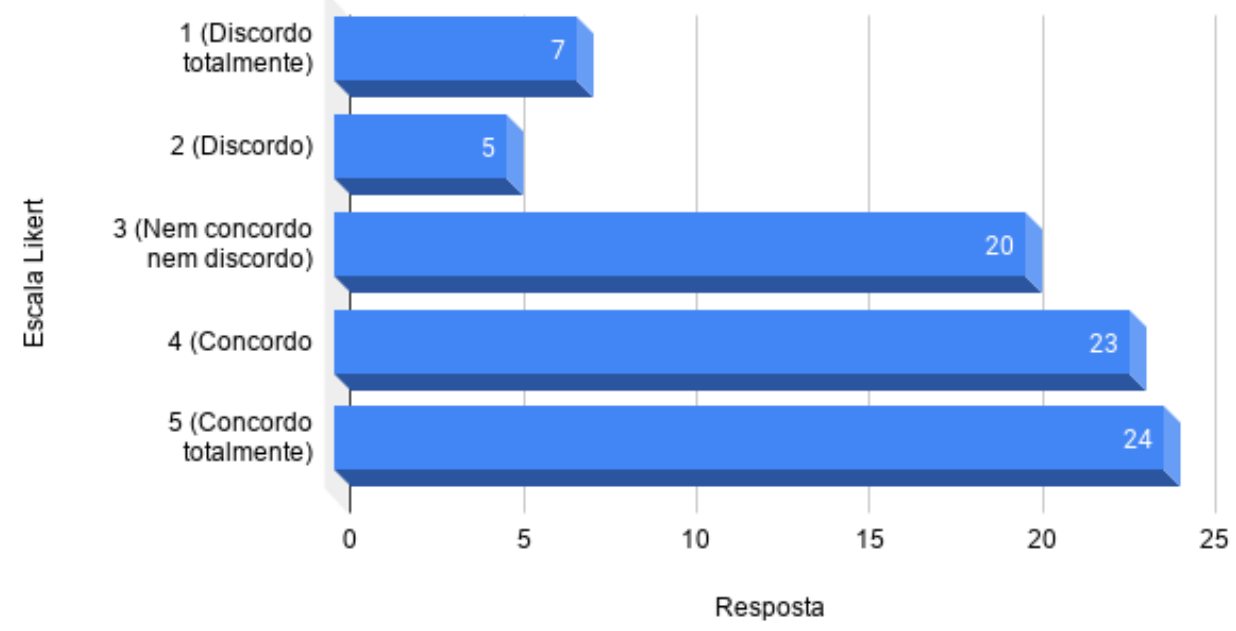

Fonte: Elaboração dos autores. 
Reforma do ensino médio e educação remota: o que pensam os(as) estudantes do distrito federal?| Marcelo Pinheiro Cigales | Doralice Pereira de Assis | Lucas Sales de Figueredo \& Guilherme Henrique Cruz Quevedo

No que tange aos itinerários formativos, quase metade dos estudantes $(48,10 \%)$ ainda não sabe qual área seguir. Porém, aqueles que demonstraram interesse em uma área estão distribuídos da seguinte maneira: a) Matemática e suas Tecnologias (18,99\%); b) Ciências Humanas e Sociais Aplicadas $(13,92 \%)$; c) Linguagens e suas Tecnologias (11,39\%); d) Ciências da Natureza e suas Tecnologias (7,49\%). Há de se considerar que as escolas ainda não definiram o formato dos IF, sendo que a Subsecretaria de Formação Continuada de Profissionais de Educação (EAPE/DF) está realizando, no final de 2020, um curso de formação para pensar junto aos professores os formatos das eletivas orientadas e das trilhas de aprendizagem.

Ademais foram abordadas as vivências e perspectivas sobre o ensino remoto, em que foi avaliado o acesso à internet, sendo que as respostas foram, respectivamente, as opções $5(36,71 \%), 4(27,85 \%)$ e $3(21,52 \%)$. Além disso, da mesma forma verificamos que cerca de 65 estudantes (82,27\%) dos estudantes sentem que a sua formação está sendo prejudicada de alguma maneira, como pode ser visto no Gráfico 2, sendo que 35,44\% afirma conhecer algum colega que não possui acesso à internet.

\section{GRÁFICO 2 - PERCEPÇÃO DOS(AS) ESTUDANTES SOBRE A FORMAÇÃO ESTAR SENDO PREJUDICADA DEVIDO AO ENSINO REMOTO}

\section{Você sente que sua formação está sendo prejudicada com o ensino remoto?}

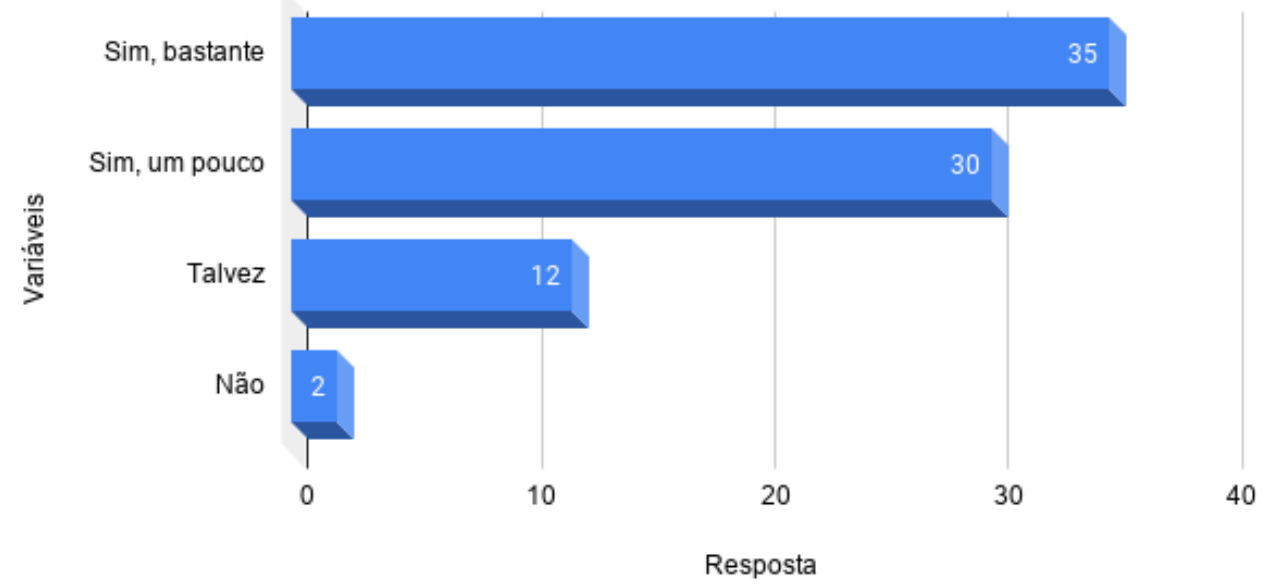


Reforma do ensino médio e educação remota: o que pensam os(as) estudantes do distrito federal?| Marcelo Pinheiro Cigales | Doralice Pereira de Assis | Lucas Sales de Figueredo \& Guilherme Henrique Cruz Quevedo

\section{Fonte: Elaboração dos autores.}

Com relação à percepção dos(as) respondentes sobre as transformações no ensino médio empreendidas pela reforma, 41 (51,9\%) percebem de forma positiva, destacando a flexibilidade e o dinamismo na organização dos estudos. Segundo eles(as), a transformação curricular permite a ênfase em interesses pessoais. De acordo com uma respondente (R), "antes era uma coisa mais padronizada, agora podemos incluir nossos interesses" (R01, estudante parda, 15 anos). Além desse aspecto, também foi citada a oferta de novas disciplinas: "dá a oportunidade para nós alunos aprender algo diferente" (R02, estudante parda, 17 anos). E também: "Foi uma reforma que, apesar de ser vista com maus olhos pelas pessoas que só ouviram falar, foi e é uma revolução na educação" (R03, estudante negra, 15 anos).

Em contrapartida, um grupo de sete respondentes $(8,8 \%)$ tem outra visão sobre a reforma, percebendo-a de modo negativo. Dentre eles, os principais pontos elencados foram a dificuldade com o aumento do número de disciplinas e o tempo de aula reduzido. Nessa linha, vale sublinhar as respostas de dois desses estudantes: "Antes era melhor, depois, ficou mais complicada, os alunos tem mais matéria para estudar, fica mais complicado de aprender" (R04, estudante, sem autoidentificação de cor, 17 anos); "Sinceramente não concordo, prefiro como era antes, não consigo aprender nada com o tempo de aula reduzido" (R05, estudante branca, 15 anos).

Outro estrato de dez respondentes (12,6\%) apresentou certa indiferença em suas respostas com relação às mudanças, mobilizando adjetivos como "regular" e "normal” para expressarem suas percepções. Por outro lado, um grupo de seis estudantes $(7,6 \%)$ relatou estarem se sentindo perdidos e confusos com as mudanças. Já um grupo de quatro respondentes (5\%) confundiu a Reforma do Ensino Médio com o ensino remoto, como pode ser ilustrado a partir do seguinte relato: "Antes era mais fácil porque tinha o professor sempre auxiliando, agora está um pouco mais complicado, porém a 
Reforma do ensino médio e educação remota: o que pensam os(as) estudantes do distrito federal?| Marcelo Pinheiro Cigales | Doralice Pereira de Assis | Lucas Sales de Figueredo \& Guilherme Henrique Cruz Quevedo

escola está fazendo de tudo para dar todo apoio necessário" (R06, estudante branca, 16 anos).

No intuito de observar o quanto os(as) estudantes se sentem informados sobre o Novo Ensino Médio, perguntamos se havia alguma dúvida. Nessa questão, 55 respondentes (70\%) disseram não possuir dúvida alguma ou pelo menos não até o momento de resposta ao questionário. Foram 14 respondentes (18\%) os que tiveram dúvidas, entre eles a mais comum acerca do formato de avaliação e aprovação, dentre as quais destaca-se: "Como funciona as notas se continua igual era antes" (R08, estudante parda, 15 anos). Outra respondente questionou sobre o ensino remoto: "Se as tarefas que eles postam valem ponto? E como vão ser as provas?” (R09, estudante negra, 15 anos). Houve ainda estudantes que se mostraram em dúvida sobre as consequências desse novo formato: "A minha dúvida é sobre quais vão ser os efeitos dessas mudanças" (R10, estudante parda, 15 anos); "Como isso afeta meu currículo profissional?” (R05, estudante branca, 15 anos).

Com relação ao ensino remoto, uma parcela de 38 respondentes $(48,1 \%)$ rejeita por completo o formato, alegando como pontos negativos as dificuldades de aprendizagem e concentração, os problemas com o domínio das plataformas e as condições de acesso à internet. Nesse eixo, vale frisar os seguintes relatos: "Horrivel, muitas vezes é dificil acessar a internet, só quando eu coloco crédito porque na minha casa não tem Wi-Fl' (R05, estudante branca, 15 anos); "Bom acho que tem mais dificuldades pois têm alunos ou até mesmo os professores que não sabe utilizar muito bem a tecnologia" (R11, estudante parda, 15 anos).

Outro grupo de 13 respondentes (16,45\%) se caracteriza por estarem enfrentando dificuldades com a adaptação, porém alguns deles estão otimistas com uma provável adaptação, como ilustra a seguinte resposta: "Está sendo uma experiência um pouco difícil, mas com o tempo vou me acostumando" (R12, estudante negra, 15 anos). Já outro conjunto, composto por oito respondentes $(10,12 \%)$, apresenta opiniões que ponderam aspectos negativos e positivos do ensino remoto, como bem exemplifica o seguinte relato: 
Reforma do ensino médio e educação remota: o que pensam os(as) estudantes do distrito federal?| Marcelo Pinheiro Cigales | Doralice Pereira de Assis | Lucas Sales de Figueredo \& Guilherme Henrique Cruz Quevedo

\begin{abstract}
Bom e ruim. Bom porque temos as aulas gravadas sempre que a gente não entender algo, podemos ir lá e assistir quantas vezes quisermos. E ruim porque não é a mesma coisa, estamos acostumados a ver as pessoas, e querendo ou não a explicação não é mesma, quando o professor tá explicando a gente pode tirar dúvidas imediatamente, e já na plataforma temos que digitar toda aquela dúvida, escrever de um jeito que o professor entenda, e no presencial não, só da gente olhar pra ele, ele já sabe se estamos com dúvida ou não (R13, estudante branca, 15 anos).
\end{abstract}

Também ressaltamos um grupo de 17 respondentes (21,51\%), entusiastas do ensino remoto, elogiando-o principalmente pela flexibilidade na agenda de estudos: "É até bom porque ficamos de certa forma mais folgados com o prazo de 15 dias para entregar as tarefas facilitando a vida de quem trabalha ou faz outras coisas no dia a dia" (R14, estudante branco, 15 anos). Nesse grupo também há aqueles que preferem tal formato por condições pessoais, como expresso na seguinte resposta: "Está sendo bom, pois se estivesse sendo presencial eu não poderia participar pois minha mãe está doente" (R15, estudante branca, 15 anos).

No que se refere às dificuldades para estudar em casa, uma parcela de 14 respondentes $(17,72 \%)$ listou os problemas com internet e equipamentos como os principais entraves enfrentados, o que é ainda mais presente para os(as) estudantes residentes de zona rural. Os seguintes relatos são ilustrativos dessas dificuldades: "É muito dificil pra mim, pois meu celular não é bom. E além disso eu estou na roça o Wifi é péssimo!" (R16, estudante parda, 16 anos); "O notebook é compartilhado com todos os meus familiares, minha mãe é professora, então tem que estar no computador o dia todo" (R03, estudante negra, 15 anos).

Outro grupo, também composto por 14 respondentes $(17,72 \%)$, elencou os problemas de concentração e organização como as principais dificuldades, o que pode ser conferido na seguinte resposta: "Concentrar é difícil, e eu não sei o porquê as aulas online são piores pra aprender, parece que você escuta a aula, lê, e não aprende nada no final” (R17, estudante pardo, 15 anos). 
Reforma do ensino médio e educação remota: o que pensam os(as) estudantes do distrito federal?| Marcelo Pinheiro Cigales | Doralice Pereira de Assis | Lucas Sales de Figueredo \& Guilherme Henrique Cruz Quevedo

Nessa mesma linha, outro estrato de oito respondentes (10,12\%) alegou a presença constante de barulhos e distrações, bem como outros problemas com o próprio ambiente da casa, que nem sempre conta com espaços adequados para estudo. Por outro lado, uma parcela de 10 estudantes $(12,65 \%)$ destacou as dificuldades de compreensão do conteúdo como os principais obstáculos enfrentados, o que é apresentado na seguinte resposta: "A dificuldade é em relação a compreensão dos conteúdos, não consigo estudar pra decorar o assunto. Não é a mesma coisa do que ter um professor presente" (R18, estudante parda, 15 anos).

Um grupo de nove estudantes $(11,4 \%)$ afirmou que a ausência do professor, ou da dinâmica adotada por ele, vem sendo um dos maiores desafios durante o ensino remoto, o que pode ser visto no seguinte relato:

\begin{abstract}
Muitas das vezes é necessária uma orientação para a realização de algumas atividades e conversar com o professor pela plataforma ou redes sociais não ajuda muito não até porque acho que as atividades e evolução dos alunos nas aulas presenciais e até um pouco melhor porque querendo ou não temos uma vida social lá e acho que isso faz falta e atinge os alunos de certa forma (R14, estudante branco, 15 anos).
\end{abstract}

No fim do questionário, deixamos um espaço aberto para dúvidas, sugestões e comentários sobre o novo formato do ensino médio e sobre o ensino remoto. Um dos comentários que mais ocorreu foi sobre dar continuidade ao ano letivo no formato remoto. Quatro alunas disseram ser melhor desconsiderar o semestre online e refazer presencialmente, como exemplifica a seguinte resposta:

\footnotetext{
Por mais que atrase, que por um lado estamos nos atrasando em relação a conteúdo, seria melhor cancelar o ano letivo e tentar voltar com mais cuidado por conta dessa pandemia, no ano que vem, seria bem melhor pois ensino a distância está sendo muito ruim (R19, estudante parda, 15 anos).
}

No rol de reclamações, houve pedidos para que os professores respondessem mais as questões feitas na plataforma online e que diminuíssem a quantidade de atividades enviadas, como mostra os seguintes comentários: "Em relação ao ensino não presencial, acho que os professores deveriam ficar mais atento a plataforma, pois tem perguntas lá que não foram respondidas até hoje" (R20, estudante parda, 16 anos); "Está sendo bastante complicado, 
Reforma do ensino médio e educação remota: o que pensam os(as) estudantes do distrito federal?| Marcelo Pinheiro Cigales | Doralice Pereira de Assis | Lucas Sales de Figueredo \& Guilherme Henrique Cruz Quevedo

principalmente para mim que estou fazendo tudo desde o começo, e são muitas atividades [...]" (R01, estudante parda, 15 anos).

Houve relatos apontando a necessidade de maior organização e o cuidado com os estudantes que não possuem acesso à internet e aparelhos eletrônicos para o ensino remoto. Nesse sentido, o seguinte comentário sintetiza esse desconforto por parte de alguns estudantes: "Acho que o ensino não presencial deveria ser mais organizado, e as escolas, o governo e a secretária deveriam pensar mais nos alunos que não tem a possibilidade de ter acesso a internet nem a nem um aparelho eletrônico" (R03, estudante negra, 15 anos).

Uma aluna que está tendo apenas atividades assincronas, aproveitou o espaço para cobrar aulas ao vivo. Ela escreveu: "Acho que seria bom ter aulas ao vivo, seria melhor para compreender os assuntos, pois só lê, pesquisar e vê as aulas gravadas não é a mesma coisa" (R07, estudante parda, 15 anos). Notamos que as respostas apresentam as dificuldades do ensino remoto, tais como: autogestão do tempo de estudo, dificuldades com o acesso à internet ou às Tecnologias de Informação e Comunicação (TICS), ausência de espaço adequado dentro de casa para o estudo remoto, que se complexifica a partir dos relatos sobre a falta de silêncio, ou até mesmo quanto à interação com os colegas e professores(as) na escola. Ao mesmo tempo, parece-nos que a interação simultânea se apresenta como relevante e necessária no processo de aprendizagem desses alunos.

Houveram algumas sugestões sobre as matérias eletivas na parte dos IF. Observamos que parte dos respondentes entendem essas matérias como algo que deva ser articulado com seus interesses pessoais: "Poderia muito ter algo sobre dança [...]" (R21, estudante parda, 15 anos). Outros abordam uma possibilidade mais prática e voltada ao mercado de trabalho: "Queria que tivesse atividade empresa" (R23, estudante parda, 17 anos).

Eu queria que eles aplicassem disciplinas que teriam mesmo importância na nossa vida, tipo culinária [onde] iremos ser preparados para o nosso dia a dia, aprendermos sobre como administrar o nosso 
Reforma do ensino médio e educação remota: o que pensam os(as) estudantes do distrito federal?| Marcelo Pinheiro Cigales | Doralice Pereira de Assis | Lucas Sales de Figueredo \& Guilherme Henrique Cruz Quevedo

dinheiro, termos um acesso a profissões para que não venhamos ter dúvida no futuro (R22, estudante branco, 15 anos).

Parece-nos que a proposição do Novo Ensino Médio sobre o protagonismo dos jovens está de acordo com as expectativas da maioria dos respondentes, uma vez que eles(as) visualizam a participação na construção da parte diversificada do currículo. No entanto, um olhar mais crítico pode apontar as lacunas e incongruências da Lei $\mathrm{n}^{\circ} 13.415$, de 2017, que aprovou a Reforma do Ensino Médio, justificada em grande medida pela necessidade de aumentar a qualidade do ensino médio, acrescido pelo clamor de torná-lo mais atrativo aos alunos, o que, no fundo, desconsidera a falta de investimento, infraestrutura, carreira docente e valorização do magistério (FERRETTI, 2017).

Chamou-nos a atenção a percepção dos(as) respondentes com relação ao quanto se sentem informados sobre o Novo Currículo do Ensino Médio. A pesquisa de Michetti (2020) nos faz pensar nos conceitos de consensualização e concertação discursiva presentes na aprovação da BNCC, em que as críticas dos representantes do campo acadêmico e sindical foram dissolvidas a partir de estratégias de legitimação, como o pouco espaço de fala desses agentes ou a pressa na aprovação do documento. Observamos, portanto, que a aprovação do novo currículo, que interessa grupos empresariais e econômicos, tais como a Fundação Lemann, articula diversas redes e espaços sociais (político, midiático e acadêmico) a fim de levar adiante seus interesses diante de um mercado educacional brasileiro. No entanto, temos que considerar que a articulação com essas redes tenha se dado via Consed, com diferentes graus de interdependência em cada estado, e que merece ser investigado com maior profundidade.

Nesse sentido, partimos da hipótese de que a resposta positiva por parte dos estudantes sobre o quanto eles se sentem informados sobre o novo currículo pode estar atrelada a um discurso produzido no campo midiático atrelado a gestão educacional dos governos Michel Temer (2016-2018) e Jair Bolsonaro (2018-2022). Um currículo ainda pouco vivenciado pelas práticas escolares, o que estaria na base para as respostas positivas com relação à sua 
Reforma do ensino médio e educação remota: o que pensam os(as) estudantes do distrito federal?| Marcelo Pinheiro Cigales | Doralice Pereira de Assis | Lucas Sales de Figueredo \& Guilherme Henrique Cruz Quevedo

transformação. Igualmente se faz necessário verificar, em futuras pesquisas, a comunicação intra-escolar e entre os diferentes âmbitos da gestão no DF.

Mas, se por um lado, destacam-se os interesses desses grupos econômicos sobre a privatização da educação no Brasil, por outro lado temos que considerar as “consequências impremeditadas da ação” (GIDDENS, 2009) que a implementação dessa reforma pode causar nas escolas e na organização dos componentes curriculares por área de conhecimento. $\mathrm{O}$ que poderíamos pensar em termos de mobilização pedagógica, política e social da escola pública neste momento de isolamento social e fechamento físico das escolas devido à pandemia da Covid-19? Pensamos que essas questões merecem ser aprofundadas em trabalhos futuros, ainda que os dados aqui apresentados nos indiquem algumas questões:

a) O novo currículo do ensino médio deve ser um trabalho coletivo, democrático e que reconheça o “[...] universalismo inerente ao pensamento científico e o relativismo ensinado pelas ciências humanas, atentas à pluralidade dos modos de vida, dos saberes e das sensibilidades culturais" (BOURDIEU, 2019, p. 239). Ao analisarmos em termos nacionais, percebemos que o currículo do ensino médio e a BNCC não foram processos democráticos de fato, pois foram atravessados por processos políticos autoritários. No entanto, a tessitura do currículo, neste momento, está passando pelo âmbito da conjuntura políticoeducacional dos estados e municípios, que podem surtir processos mais plurais, incluindo a participação dos diferentes agentes da comunidade escolar (pais, alunos, professores e gestores). É nesse sentido que a diversificação das aprendizagens por área do conhecimento, tendo em vista os objetivos de aprendizagem, pode tornar a escola um local que reconheça, como afirma Bourdieu (2019, p. 239), uma "pluralidade dos modos de vida, dos saberes e das sensibilidades culturais". No entanto, para que isso ocorra é preciso investir na formação dos(as) professores(as) no país, institucionalizando de fato a profissão docente 
Reforma do ensino médio e educação remota: o que pensam os(as) estudantes do distrito federal?| Marcelo Pinheiro Cigales | Doralice Pereira de Assis | Lucas Sales de Figueredo \& Guilherme Henrique Cruz Quevedo

que requer a criação de mercado de trabalho (abertura de concursos), fontes de financiamento para a formação continuada e, principalmente, a profissionalização via criação de concurso, carreira e valorização salarial. Questões que nos parecem problemáticas do ponto de vista político-institucional, dada a conjuntura de cortes de investimento na educação, além do congelamento de gastos em educação nas próximas duas décadas, conforme a PEC do teto de gastos, aprovada em 2016 pelo Congresso Nacional (FERRETTI, 2017);

b) A escola pública como direito social não pode continuar fechada simbolicamente às classes ou grupos sociais que mais precisam dela neste momento de crise sanitária, politica, trabalhista e educacional. Ocupar simbolicamente a escola representa dar voz aos estudantes e professores no processo de repensar a educação remota, reivindicar uma política pública educacional que invista na aquisição de equipamentos eletrônicos, acesso à internet e mapeamento das dificuldades financeiras e familiares dos(as) estudantes mais empobrecidos, para que possamos impedir o abandono e a evasão escolar de uma geração de jovens estudantes que estão impedidos pelas condições objetivas da crise de ter acesso ao espaço físico e simbólico da escola. Os dados deste trabalho nos indicam caminhos para o enfrentamento da questão: repensar uma transposição didática dos conteúdos e das práticas escolares. Isso significa dizer que a escola não se resume a conteúdos disciplinares, mas a saberes produzidos coletivamente por meio das relações sociais estabelecidas no seu espaço físico. Como podemos transpor isso para o ensino remoto digital? Poderia haver integração entre a televisão, a rádio e as tecnologias digitais mais contemporâneas nessa transposição escolar, fazendo chegar a um maior número de pessoas os saberes da escola?

c) O ensino de Ciências Humanas frente às mudanças curriculares é controverso e precisa ser estudado a nivel estadual. No caso do DF, os dados desta pesquisa nos indicam que a área de CHSA é requisitada por parte dos respondentes, mas em termos objetivos nos preocupa o baixo 
Reforma do ensino médio e educação remota: o que pensam os(as) estudantes do distrito federal?| Marcelo Pinheiro Cigales | Doralice Pereira de Assis | Lucas Sales de Figueredo \& Guilherme Henrique Cruz Quevedo

número de professores efetivos no contexto nacional, assim como a disciplina de Sociologia estar sendo lecionada por professores de outras áreas (BODART; SAMPAIO-SILVA, 2019). Cabe destacar que o estudo de Raizer, Caregnato, Mocelin e Pereira (2017), ao analisarem o Censo Escolar de 2015, demonstra a baixa formação dos(as) professores(as) de Ciências Humanas com as disciplinas que lecionam na educação básica: Sociologia, com apenas $11,8 \%$ de professores(as) formados na área, seguida de Filosofia, com 21,8\%, Geografia, com 57,1\%, e História, com 61,7\% (RAIZER; CAREGNATO; MOCELIN; PEREIRA, 2017, p. 18). Na prática, isso pode representar uma hierarquia no interior dos currículos que passam a ser regidos pela interdisciplinaridade, objetivos de aprendizagem, projetos, trilhas de aprendizagem e outras formas que descaracterizam o currículo por disciplinas. Por outro lado, também podemos pensar que as atuais mudanças podem impulsionar a demanda por profissionais formados na área de Ciências Sociais. Estudos como os de Bodart e Feijó (2020) e Silva e Neto (2020) destacam certa "sociologização" da BNCC, tendo em vista que vários elementos presentes nesses objetivos estão em diálogo direto com conceitos da Sociologia, tais como: democracia, política, cidadania, cultura, trabalho, mobilização, protagonismo juvenil, identidade, entre outros. Ao nos debruçarmos sobre os objetivos de aprendizagem do Currículo em Movimento do DF, percebemos que várias dessas temáticas também estão presentes.

\section{Considerações finais}

Apesar de breve, o artigo buscou dar visibilidade para os estudantes do ensino médio que vivenciam, neste ano de 2020, os desafios da implementação da Reforma do Ensino Médio no DF e o ensino remoto implementado devido à Covid-19. Destacamos que a implementação da Reforma foi impactada pela necessidade do distanciamento social causado pela pandemia. Nossa análise precisou se estender para abarcar também a 
Reforma do ensino médio e educação remota: o que pensam os(as) estudantes do distrito federal?| Marcelo Pinheiro Cigales | Doralice Pereira de Assis | Lucas Sales de Figueredo \& Guilherme Henrique Cruz Quevedo

nova realidade do ensino remoto, o que exigiu que tivéssemos que nos adaptar a essa situação levantando outras hipóteses no decorrer da pesquisa.

Entre os principais resultados, podemos destacar que a implementação da Reforma do Ensino Médio no DF teve continuidade no ano de 2020, no entanto, com a implementação do ensino remoto devido à Covid19, houve o atraso desse processo. A pesquisa demonstrou que vários respondentes têm dificuldades ou sentem que sua formação está sendo prejudicada neste momento de ensino remoto. Além disso, é preciso destacar que parte significativa dos respondentes estão otimistas com a implementação da Reforma do Ensino Médio, apesar de ainda precisarmos avançar na avaliação sobre como o currículo se estabelecerá no DF, pois várias questões ainda estão em aberto, tais como: a) qual a possibilidade de as escolas ofertarem os cinco IF?; b) haveria um risco do IF de CHSA se tornar elitizado, tendo em vista que, se ofertado apenas em algumas escolas, atrairia somente aqueles(as) estudantes com conhecimento prévio sobre a profissão nessas áreas, ou aqueles(as) que têm interesse em seguir estudando a área no ensino superior?; c) como será a implementação do IF da Educação Técnica e Profissional? Uma vez que esse IF reconhece o "notório saber" como sendo suficiente para orientar ou trabalhar com estudantes do ensino médio, acrescido da abertura de parcerias com o setor privado e da educação à distância, direcionaria os estudantes-trabalhadores para essa formação em específico, uma vez que as condições objetivas filiadas à necessidade de trabalho dessa juventude não permitiria a escolha de outros IF?

Sendo a universidade uma produtora de conhecimento e formadora de profissionais, é relevante que seja estabelecida uma ponte entre a escola e a academia para que a realidade e o ensino não sejam desconexos, e que as demandas advindas das escolas façam parte das soluções, da formação e da produção de conhecimento dentro da universidade. Portanto, o acompanhamento do processo de implementação da Reforma do Ensino Médio é necessário para compreendermos não somente as dinâmicas políticas curriculares mais amplas, mas também como o currículo escolar se configura na contemporaneidade, lançando luz sobre as dinâmicas que as disciplinas 
Reforma do ensino médio e educação remota: o que pensam os(as) estudantes do distrito federal?| Marcelo Pinheiro Cigales | Doralice Pereira de Assis | Lucas Sales de Figueredo \& Guilherme Henrique Cruz Quevedo

de História, Geografia, Filosofia e Sociologia passam a protagonizar a partir de agora na área de Ciências Humanas e Sociais Aplicadas. Esse acompanhamento também nos possibilita pensar a interdisciplinaridade entre esses componentes curriculares, buscando outros caminhos de ensino, ainda que as condições objetivas com relação ao investimento, à gestão e à estratégia na política educacional do país tenham se mostrado cada vez mais problemáticas.

\section{Referências:}

ANTUNES, Jéssica. Adiado retorno de aulas presenciais na rede pública. Agência Brasil. Brasília, Distrito Federal, 2020. Disponível em: https: / /www.agenciabrasilia.df.gov.br/2020/08/19/adiado-retorno-deaulas-presenciais-na-rede-publica/. Acesso em nov. de 2020.

ARRUDA, Eucidio Pimenta. Educação remota emergencial: elementos para políticas públicas na educação brasileira em tempos de Covid-19. EmRedeRevista de Educação a Distância, v. 7, n. 1, p. 257-275, 2020.

BERNSTEIN, Basil. A estruturação do discurso pedagógico: classe, códigos e controle. Petrópolis: Vozes, 1996.

BODART, Cristiano; FEIJÓ, Fernanda. Ciências Sociais no Currículo do Ensino Médio Brasileiro. Revista Espaço do Curriculo, v. 13, n. 2, p. 219234, 14 abr. 2020.

BODART, Cristiano das Neves; SILVA-SAMPAIO, Roniel. Quem leciona Sociologia após 10 anos de presença no Ensino Médio brasileiro? In: BODART, Cristiano das Neves; LIMA, Wenderson Luan dos Santos. O ensino de Sociologia no Brasil, v. 1. Maceió: Editora Café com Sociologia, p. 35-61, 2019.

BRASIL. Lei $\mathbf{n}^{\circ}$ 9.394, de 20 de dezembro de 1996. Estabelece as diretrizes e bases da educação nacional. Disponivel em: http://www.planalto.gov.br/ccivil_03/leis/19394.htm Acesso em: 7 set. 2020.

Lei no 13.415, de 16 de fevereiro de 2017. Altera as Leis no 9.394, de 20 de dezembro de 1996 [...]. Brasilia: 2017.

Base Nacional Comum Curricular: Ensino Médio. Brasília: MEC/Secretaria de Educação Básica, 2018.

- Portaria No. 1.432, de 28 de dezembro de 2018. Estabelece os referenciais para elaboração dos itinerários formativos conforme preveem as 
Reforma do ensino médio e educação remota: o que pensam os(as) estudantes do distrito federal?| Marcelo Pinheiro Cigales | Doralice Pereira de Assis | Lucas Sales de Figueredo \& Guilherme Henrique Cruz Quevedo

Diretrizes Nacionais do Ensino Médio. DOU, 05/04/2019. Ed. 66, Seção 1. p. 94, 2018.

BOURDIEU, Pierre. PASSERON, Jean-Claude. A Reprodução: elementos para uma teoria do sistema de ensino. Rio de Janeiro: Livraria Francisco Alves, 1992.

BOURDIEU, Pierre. Razões práticas: sobre a teoria da ação. 11. ed. Campinas Papirus, 1996.

BOURDIEU, Pierre. Proposições para o ensino do futuro: Relatório do Collège de France (1985). In: VALLE, Ione Ribeiro; SOULIÉ, Charles. (Orgs.). Pierre Bourdieu: uma sociologia ambiciosa da Educação. Florianópolis: Editora da UFSC, p. 235-266, 2019.

BRUNETTA, Antonio Alberto; CIGALES, Marcelo Pinheiro. Dossiês sobre ensino de sociologia no Brasil (2007-2015): temáticas e autores(as). Latitude, v. 12, n. 1, p. 171, 2019.

CARLA, Maria. Mais de 120 mil alunos da escola pública do Distrito Federal não conseguem acessar a EAD. SINPRO, Brasília, Distrito Federal, 2020. Disponivel em: https://www.sinprodf.org.br/mais-de-100-mil-estudantesda-escola-publica-do-df-nao-conseguem-ter-acesso-a-ead/. Acesso em: 8 nov. 2020.

DISTRITO FEDERAL. Companhia de Planejamento do Distrito Federal CODEPLAN. Pesquisa Distrital por Amostra de Domicílio - Recanto das Emas - PDAD 2018, Brasília, 2019. Disponível em: http:/ /www.codeplan.df.gov.br/wp-content/uploads/2020/06/Recanto-dasEmas.pdf. Acesso em: 10 nov. 2020.

SEE. Proposta Pedagógica: Centro de Ensino Médio 804 do Recanto das Emas. Brasília: 2018. Disponivel em: http://www.educacao.df.gov.br/wpconteudo/uploads/2018/07/pp_cem_804_recanto_das_emas.pdf. Acesso em: 7 set. 2020 .

. LEI No 510, DE 28 DE JULHO DE 1993. Cria a Região Administrativa do Recanto das Emas. DODF DE 29.07.1993. Disponível em: http://www.sinj.df.gov.br/sinj/Norma/48469/Lei_510_28_07_1993.html. Acesso em: 16 nov. 2020.

Decreto $\mathrm{N}^{\circ}$ 40.509, DE 11 DE MARCO DE 2020. Dispõe sobre as medidas para enfrentamento da emergencia de saúde pública de importancia internacional decorrente do novo coronavírus, e dá outras providencias. DOUDF. Brasilia, DF, 2020a. Disponivel em: https://static.poder360.com.br/2020/03/decreto-40.509.pdf. Acesso em: 16 nov. 2020. 
Reforma do ensino médio e educação remota: o que pensam os(as) estudantes do distrito federal?| Marcelo Pinheiro Cigales | Doralice Pereira de Assis | Lucas Sales de Figueredo \& Guilherme Henrique Cruz Quevedo

Decreto $\mathrm{N}^{\circ} 40.520$, de 14 de março de 2020. Dispõe sobre as medidas para enfrentamento da emergência de saúde pública de importância internacional decorrente do novo coronavirus, e da outras providências. DOUDF, 14/03/2020. Brasília, Distrito Federal, 2020b. Disponivel em: http://www.sinj.df.gov.br/sinj/Norma/ed3d931f353d4503bd35b9b34fe747f 2/Decreto_40520_14_03_2020.html. Acesso em: 16 nov. 2020.

. Decreto $\mathrm{N}^{\circ} 40.539$, de 19 de março de 2020. Dispõe sobre as medidas para enfrentamento da emergência de saúde pública de importância internacional decorrente do novo coronavírus, e dá outras providências. DOUDF. Brasília, Distrito Federal, 2020c. Disponivel em: http://www.sinj.df.gov.br/sinj/Norma/ac087b76d5f34e38a5cf3573698393f 6/Decreto_40539_19_03_2020.html. Acesso em: 16 nov. 2020.

. Decreto $\mathrm{N}^{\circ}$ 40550, de 23 de março de 2020. Dispõe sobre as medidas para enfrentamento da emergência de saúde pública de importância internacional decorrente do novo coronavírus, e dá outras providências. DOUDF, Brasília, Distrito Federal, 2020d. Disponivel em: http://www.sinj.df.gov.br/sinj/Norma/2daec529965741e29602314371cc37 bf/Decreto_40550_23_03_2020.html. Acesso em: 16 nov. 2020.

. Decreto $\mathrm{N}^{\circ} 40,583$, de $1^{\circ}$ de abril de 2020. Dispõe sobre as medidas para enfrentamento da emergência de saúde pública de importância internacional decorrente do novo coronavírus. DOUDF, Brasília, Distrito Federal. 2020e. Disponivel em: http://www.sinj.df.gov.br/sinj/Norma/e1aafOba1c0948d1aebcda7454c4a09 7/Decreto_40583_01_04_2020.html. Acesso em: 16e nov. 2020.

. Decreto $\mathrm{N}^{\circ} 40.817$, de 22 de maio de 2020. Dispõe sobre as medidas para enfrentamento da emergência de saúde pública de importância internacional decorrente do novo coronavirus e dá outras providências. DOUDF, Brasília, Distrito Federal. 2020f. Disponivel em: http://www.sinj.df.gov.br/sinj/Norma/327d72d3c115490394bb9373f942e0 30/Decreto_40817_22_05_2020.html. Acesso em: 16 nov. 2020.

. Decreto $\mathrm{N}^{\circ} 40.939$, de 02 de julho de 2020. Dispõe sobre as medidas para enfrentamento da emergência de saúde pública de importância internacional decorrente do novo coronavirus e dá outras providências. DOUDF, Brasília, Distrito Federal 2020g. Disponivel em: http://www.sinj.df.gov.br/sinj/Norma/5bfb368868304acb9d085094acb909 dd/Decreto_40939_02_07_2020.html. Acesso em: 16 nov. 2020.

Currículo em movimento do Novo Ensino Médio $\left(3^{\circ}\right.$ Versão- Minuta para consulta pública). Secretaria de Educação do Distrito Federal. Brasília, DF. 2020h. Disponivel em: http://www.educacao.df.gov.br/wp- 
Reforma do ensino médio e educação remota: o que pensam os(as) estudantes do distrito federal?| Marcelo Pinheiro Cigales | Doralice Pereira de Assis | Lucas Sales de Figueredo \& Guilherme Henrique Cruz Quevedo

conteudo/uploads /2019/08/Curr\%C3\%ADculo-do-Novo-Ensino-Médio_3aversão_4set20.pdf. Acesso em: 16 nov. 2020.

FERNANDES, Florestan. Educação e Sociedade no Brasil. São Paulo: Dominus/Edusp, 1966.

FERRETTI, Celso João. A reforma do Ensino Médio e sua questionável concepção de qualidade da educação. Estudos Avançados, v. 32, n. 93, p. 25-42, 2018.

FERREIRA, W. Fernando; ABREU, Richard J. L.; LOUZADA-SILVA, Daniel. Desafios da articulacão entre o novo ensino médio e a BNCC: o caso do Distrito Federal. Em Aberto. Brasília, v. 33 n. 107 p. 215-222, jan./abr., 2020.

FERREIRA, Vanessa; OLIVEIRA, Amurabi. O Ensino de sociologia como um campo (ou subcampo) científico. Acta Scientiarum. Human and Social Sciences, Maringá, v. 37, n. 1, p. 31-39, Jan.-June, 2015.

GARCIA, Leila Posenato. Uso de máscara facial para limitar a transmissão da COVID-19. Epidemiol. Serv. Saúde, Brasília, v. 29, n. 2, e2020023, 2020.

GIDDENS, Anthony. A Constituição da Sociedade. 3. ed. São Paulo: Editora Martins Fontes, 2009.

MICHETTI, Miqueli. Entre a legitimação e a crítica: as disputas acerca da Base Nacional Comum Curricular. Revista Brasileira de Ciências Sociais, São Paulo, v. 35, n. 102, 2020.

RAIZER, Leandro; CAREGNATO, Celia; MOCELIN, Daniel; PEREIRA, Thiago. O ensino da disciplina de Sociologia no Brasil: diagnóstico e desafios para a formação de professores no Brasil. Revista Espaço Acadêmico, Maringá. n. 190, p. 15-26, 2017.

RATTS, Alex; RIOS, Flavia. Lélia Gonzalez. São Paulo: Selo Negro, 2020.

SILVA, Ileizi F.; NETO, Henrique. O processo de elaboração da Base Nacional Comum Curricular (BNCC) no Brasil e a Sociologia (2014-2018). Revista Espaço do Curriculo, v. 13, n. 2, p. 262-283, 20 abr. 2020. 